\title{
Intertemporal Discounting and Policy Selection
}

\author{
Juan Carlos Conesa and Carlos Garriga
}

\begin{abstract}
The choice of the intertemporal discount rate affects the measurement of the tax burden of different age cohorts. Small changes in the discount rate affect not only the magnitude of the measured changes, but also the ranking of policies using that metric. The authors illustrate this problem in the context of neutral Social Security reforms. By construction, these policies do not change allocations; hence, they also do not change welfare. However, depending on the choice of the discount rate, one could reach different (and possibly opposite) conclusions regarding the desirability of such policies. (JEL E62, H21)
\end{abstract}

Federal Reserve Bank of St. Louis Review, March/April 2013, 95(2), pp. 165-79.

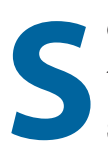

everal methods can be used to evaluate the impact of alternative fiscal policies. One of the most widely used methods, generally referred to as "generational accounting," consists of computing the net present value of taxes, net of transfers, for each age cohort. A key ingredient of this method is the choice of the intertemporal discount rate. As is well known, this choice affects the magnitude of the measured impact of a given policy. In this article, we use examples and a quantitative simulation to show that the choice of the discount rate can, in fact, reverse the ranking of alternative policies.

We proceed as follows to illustrate our point. Suppose a government considers policy B as an alternative to the existing policy A. Following our previous work (Conesa and Garriga, 2008a), it is easy to construct examples where policy B has no real effects on the economy (i.e., the levels of output, employment, consumption, and welfare remain the same as with policy A). However, the methodology would rank policy A above policy B (or vice versa) for different discount rates.

The resulting implications are important for policy evaluation and suggest great caution in the quantitative evaluation of policies that might be implemented in the near future. The recent financial crises in the United States will leave a huge hole in taxpayers' pockets. The economic slowdown has triggered an unprecedented accommodative response from the U.S. Department of the Treasury and the Federal Reserve that must be paid for in the future. In addition, future

Juan Carlos Conesa is an associate professor at the Universitat Autònoma de Barcelona. Carlos Garriga is a research officer at the Federal Reserve Bank of St. Louis. The authors are thankful for comments from Bill Gavin, Fernando Martin, and YiLi Chien. Juan Carlos Conesa acknowledges support through the Academia Prize awarded by the Institució Catalana de Recerca i Estudis Avançats (ICREA) for excellence in research funded by the Generalitat de Catalunya. He also received funding (grant No. ECO2012-32392) from the Ministry of Economy and Competitiveness.

(c) 2013, The Federal Reserve Bank of St. Louis. The views expressed in this article are those of the author(s) and do not necessarily reflect the views of the Federal Reserve System, the Board of Governors, or the regional Federal Reserve Banks. Articles may be reprinted, reproduced, published, distributed, displayed, and transmitted in their entirety if copyright notice, author name(s), and full citation are included. Abstracts, synopses, and other derivative works may be made only with prior written permission of the Federal Reserve Bank of St. Louis. 


\section{Conesa and Garriga}

demographic changes will have an important impact not only on labor markets and the tax bill for social insurance programs such as Social Security and Medicare, but also on tax revenue collection. The magnitude of these fiscal adjustments ultimately needs to be determined based on intergenerational equity (current versus future taxpayers) and incentives (mitigating the distortions from taxation).

The advantage of generational accounting methodology is the relative ease in computing the tax burden since no specific assumptions about individual preferences, technology, and market structure are required. $\underline{1}$ It is sufficient to determine an intertemporal discount rate so the tax burden paid by future generations can be directly compared with that of the current generation. This methodology has no equilibrium concept, takes all prices as exogenously given, and does not take the general equilibrium effect into consideration. The ease of computation explains its widespread use for policy analysis in practice (e.g., by the Board of Governors of the Federal Reserve System, U.S. Department of the Treasury, the World Bank) to assess the burden of future demographics or the impact of policy reforms.

Generational accounting methodology was developed by Auerbach, Gokhale, and Kotlikoff (1991). It constructs individual specific metrics of tax incidence with the objective of identifying the individuals who currently bear the cost of taxation. The methodology uses the intertemporal budget constraint to compare any discrepancy in the level of taxes paid and transfers received by a particular cohort or subset of individuals. If the economy grows at a given rate (i.e., balanced growth), taxation and expenditure should be expected to grow at the same rate. If taxes grow at a lower rate, then some future generations will face higher taxes. In this literature, it is common practice to calculate the net tax burden that future generations must bear to achieve long-term balance in the government budget constraint. Any structural change to balance these intergenerational accounts must be captured by a change in the fiscal incidence and transfers received by each generation. As such, tax policies are compared and selected based on their ability to balance these intergenerational disparities.

One limitation of the generational accounting framework is that it ignores the impact of taxation on economic activity. To address this criticism, Fehr and Kotlikoff (1996) measured the fiscal incidence implied by the generational accounts method in a dynamic general equilibrium life cycle model. They found that generational accounts match the evolution of welfare changes for each cohort, but they err with regard to the magnitude of the utility changes. They argue that the deviation between welfare changes and generational accounts is quantitatively small when there is little change in the capital-to-output ratio that determines the equilibrium interest rate and wage rates.

We argue that the methodology suffers from problems more severe than the bias in the quantitative magnitudes. We use some simple examples as well as a quantitative model. In each case, we compare the generational accounts implied by the baseline policy with those associated with neutral tax reforms (see Conesa and Garriga, 2008a). The numerical simulations suggest that for small deviations of the discount rate, the magnitude, and even the sign, of the bias can be significant. This problem is more general and also appears in reforms with real economic effects (see Conesa and Garriga, 2013), but it is simpler to illustrate it when this is not the case. 


\section{GENERATIONAL ACCOUNTING}

We closely follow Kotlikoff's (2002) description of generational accounting methodology. The tax burden $g a_{t, k}$ in period $t$ of a cohort born in period $k$ is measured as

$$
g a_{t, k}=\sum_{s=\max \{t, k\}}^{k+d} R^{-(t-s)} \frac{\pi_{s, k}}{\pi_{t, k}} \operatorname{TAX} X_{s, k},
$$

where $T A X_{s, k}$ is taxes net of transfers paid at time $s$ by the cohort born in period $k, R$ is the discount factor, $\pi_{s, k} / \pi_{t, k}$ is the fraction of individuals surviving at time $s$, and $d$ is the life expectancy of a cohort.

Therefore, equation (1) represents the present value of the average amount of taxes paid by the survivors of cohort members born at time $k$. The TAX term includes total taxes paid minus transfer payments of different forms. If we are calculating the generational account implied by a model, all these elements are clearly specified. However, if data are used as the input, the process is a bit more involved because it includes expenditures on health care, education, and other forms of transfer programs. Auerbach, Kotlikoff, and Gokhale (2002) provide a detailed description of how to map the data into the generational accounts. However, they do not impute to any specific cohort the value of government expenditures on goods and services. The main reason for this limitation is the difficulty in assigning the benefit of government purchases to different generations.

The government intertemporal budget constraint can then be reinterpreted in terms of generational accounts as follows:

$$
\sum_{s=0}^{d} \mu_{t, t-s} g a_{t, t-s}+\sum_{s=1}^{\infty} \frac{\mu_{t+s, t+} g a_{t+s, t+s}}{R^{s}}=B_{t}+\sum_{s=1}^{\infty} \frac{G_{t+s}}{R^{s}}, t=1,2, \ldots
$$

where $\mu_{t, k}$ denotes the population weight of individuals in period $t$ of cohorts born at time $k$. The metric calculates the taxes expected to be paid by each cohort, and the population weight adjusts for the size of a given cohort.

The term $g a_{t, t-s}$ on the left-hand side of equation (2) captures the generational accounts of existing cohorts, whereas the second term adds the generational accounts of unborn cohorts discounted at rate $R$. The term on the right-hand side represents the amount of outstanding government debt $B_{t}$ (financial liabilities minus the sum of the government's financial assets and the market value of public enterprises) and the value of present and future government expenditures. The term $G_{t+s}$ represents the level of government expenditures in period $t+s$.

\section{The Intertemporal Discount Rate}

The choice of the intertemporal discount rate $R$ merits special attention because it influences the generational accounts for present and future generations. The choice becomes even more problematic in the presence of varying rates or uncertainty because then the use of the term structure or risk correction is required. Moreover, in the presence of incomplete markets, risk adjustment may be cohort specific. 


\section{Conesa and Garriga}

In standard practice, a benchmark constant discount rate is used to represent the results under alternative constant discount rates. Assuming a constant discount rate can be restrictive because the capital-to-output ratio that ultimately determines interest rates may vary in the presence of demographic shocks or as the result of different policy regimes. We argue that, in general, the choice of the intertemporal discount rate also introduces a bias when evaluating equivalent tax reforms.

\section{Generational Account Imbalances and Policy Selection}

Given the tax burden in the present generation $\left\{g a_{t, t-s}\right\}_{s=0}^{d}$ and the sequence of future expenditures $\left\{G_{t+s}\right\}_{s=1}^{\infty}$, it is possible to calculate the tax payments of future generations as a residual. If the tax burden of future generations differs very little from that of the current ones, $g a_{t, t+s} \approx$ $g a_{t, t-s}$, there are no imbalances in the lifetime taxes/transfers paid. When there are imbalances, $g a_{t, t+s} \neq g a_{t, t-s}$ it is possible to compute the adjustments to tax policy that can restore the balance. Income growth is accounted for by the common assumption that productivity and wages grow at a constant rate $g>0$. Then, it is possible to calculate the growth-adjusted generational account of future generations, denoted by $\overline{g a}$. Formally,

$$
\sum_{s=0}^{d} \mu_{t, t-s} g a_{t, t-s}+\sum_{s=1}^{\infty} \frac{\mu_{t, t+s} \overline{g a}(1+g)^{s}}{R^{s-t}}=B_{t}+\sum_{s=t}^{\infty} \frac{G_{s}}{R^{s-t}} .
$$

For example, we could solve for the percentage change in government expenditures $\Delta_{g}$ that achieves generational balance. Formally,

$$
\sum_{s=0}^{d} \mu_{t, t-s} g a_{t, t-s}+\sum_{s=1}^{\infty} \mu_{t, t+s} \overline{g a}(1+g)^{s} R^{t-s}=\sum_{s=t}^{\infty} \Delta_{g} G_{s} R^{t-s}+B_{t} .
$$

Another important element is the impact of demographic changes on the imbalance of generational accounts. Consequently, population growth of future generations can reduce imbalances in the generational policy, whereas population aging can exacerbate a larger tax burden on currently young and future cohorts.

An extensive literature uses generational accounts to measure fiscal imbalances associated with different tax reforms. For example, Gokhale et al. (2000) analyze the use of the long-term projections of the Congressional Budget Office for the United States. The authors use a 4 percent discount rate and a 2.2 percent rate of productivity growth to compute the generational imbalances; they estimate that future generations will face a lifetime tax burden 41.6 percent higher than that of existing generations. They consider five alternative policies to balance the generational accounts. The first is a 31 percent permanent increase in federal, personal, and corporate income taxes. The second is a 12 percent increase in all federal, state, and local taxes. The third policy requires cutting all transfers programs (Social Security, Medicare, Medicaid, food stamps, unemployment insurance benefits, housing support, and so on) by 21.9 percent. The final two policy options require the reduction of either all government expenditures by 21 percent or federal expenditures by 66.3 percent. The methodology has been used to evaluate other policy reforms that include a switch from income to consumption taxation (as in Altig et al., 2001) or Social Security privatization (as in Kotlikoff, Smetters, and Walliser, 2002). The methodology 
has also been applied to other countries such as the United Kingdom (as in Cardarelli, Sefton, and Kotlikoff, 2000). For an international study, see Kotlikoff and Raffelhüschen (1999).

\section{MEASUREMENT OF TAX INCIDENCE AND BIAS}

This section begins with two examples in a simple framework. In each example, the economy starts with a given tax policy A and considers an alternative policy B. We follow some of the examples in the literature and consider the case of a redistributive policy and the substitution of tax instruments (consumption taxes versus income taxes). In each case, we choose alternative fiscal policies that have no real effects on the economy but give rise to different measures of tax incidence for various intertemporal discount rates.

\section{The Simple Model}

Our simple model considers a two-period environment in which households solve a simple intertemporal consumption problem:

$$
\begin{array}{ll}
\max & u\left(c_{1}\right)+\beta u\left(c_{2}\right) \\
\text { s.t. } & c_{1}+a_{2} \leq \omega_{1}+T_{1} \\
& c_{2} \leq \omega_{2}+\left[1+\left(1-\tau_{k}\right) r\right] a_{2}+T_{2},
\end{array}
$$

where $c_{1}$ and $c_{2}$ denote consumption, $\omega_{1}$ and $\omega_{2}$ are the endowments, and $a_{2}$ is the asset level. The terms $T_{1}$ and $T_{2}$ represent a lump-sum tax (negative value) or a transfer (positive value), respectively. Because the purpose of the example is to measure the tax burden, we consider specific values for the parameters. In particular, the discount factor is $\beta=0.5$, the interest rate is $r=2$, and individuals have an income endowment of $\omega_{1}=\omega_{2}=100$ units of the consumption good. The tax policy A is entirely characterized by a capital income tax of $\tau_{k}=0.5$ and no intergenerational transfers, $T_{1}=T_{2}=0$.

Given the parameter values, it is simple to check that the optimal solution implies that $c_{1}=c_{2}=100$ and $a_{2}=0$. Therefore, taxes paid are 0 , and the present value of net taxes paid is also $g a_{A}=0$.

Example 1: Reallocation of Resources over the Life Cycle. A typical example in the literature involves changes in the distribution of resources over time such as social security privatization (see, e.g., Kotlikoff, Smetters, and Walliser, 2002). Consider a policy B where households receive a transfer in period 1 of $T_{1}=50$ and face a tax in period 2 of $T_{2}=100$ units. The capital income tax is kept at 50 percent.

The reallocation of resources over the life cycle does not alter the households' intertemporal budget constraint, as shown below:

$$
c_{1}+\frac{1}{1+\left(1-\tau_{k}\right) r} c_{2} \leq \omega_{1}+T_{1}+\frac{1}{1+\left(1-\tau_{k}\right) r}\left[\omega_{2}-T_{2}\right]
$$

or

$$
c_{1}+0.5 c_{2} \leq 150 \text {. }
$$




\section{Conesa and Garriga}

Now, the optimal consumption allocation remains the same $\left(c_{1}=c_{2}=100\right)$, but the optimal level of savings is $a_{2}=50$. The present value of taxes net of transfers is expressed as

$$
g a_{B}(R)=T_{1}-\frac{1}{R}\left[T_{2}+\tau_{k} r a_{2}\right] .
$$

The value depends on the intertemporal discount rate $R$. When $R=2$, the implied generational accounts show that households are paying more taxes $\left(g a_{B}=25\right)$ with policy B than with policy A. For a larger discount rate $(R=4)$, the results are the opposite and the households are perceived to receive net transfers $\left(g a_{B}=-20\right)$. There exists an interest rate that clearly equalizes the measure for both policies, $R=1+r=3$, but otherwise the measure shows a clear bias.

The direction of redistribution is irrelevant. Consider an alternative policy $\mathrm{C}$ that redistributes in the opposite direction, from young to old (i.e., Social Security). The policy implements a $\operatorname{tax} T_{1}=50$ in period 1 and a transfer $T_{2}=100$ in period 2 . Since the intertemporal budget constraint does not change, the optimal consumption allocation is the same, $c_{1}=c_{2}=100$, but now consumers borrow $a_{2}=-50$. Now the implied generational accounts measuring the present value of taxes net of transfers become

$$
g a_{C}(R)=-T_{1}+\frac{1}{R}\left[T_{2}-\tau_{k} r a_{2}\right] .
$$

Now, we obtain the opposite effect. When $R=2$, the implied generational accounts are lower, $g a_{C}=-25$, with policy $C$ than with policy A. With $R=4$ the opposite is true: $g a_{C}=-20$.

One of the challenges for the policymaker is the correct choice of the intertemporal discount rate. In this particular example, $R=1+r=3$ is the correct choice but, in general, there is no natural candidate for the discount rate. The example shows that a small deviation affects not only the magnitude but also the sign.

This example illustrates tax reforms that redistribute resources across time. In previous work (Conesa and Garriga, 2008a), we have shown that this neutrality holds even in the presence of labor supply distortions.

Example 2: Substitution of Consumption Taxes for Capital Taxes. Another typical example in this literature is the substitution of tax instruments (see Altig et al., 2001). We now consider an alternative policy $D$. This new policy transfers resources to period 1 through a transfer $T_{1}=10$, the capital income tax is lowered to $\tau_{k}=0.25$, and the loss of revenue is compensated with a consumption tax in period 2 of $\tau_{c, 2}=0.25$.

As in the previous examples, policy $\mathrm{D}$ does not alter households intertemporal budget constraint:

$$
\begin{gathered}
c_{1}+\frac{1}{1+\left(1-\tau_{k}\right) r}\left(1+\tau_{c, 2}\right) c_{2} \leq \omega_{1}+T_{1}+\frac{1}{1+\left(1-\tau_{k}\right) r} \omega_{2} \\
c_{1}+0.5 c_{2} \leq 150 .
\end{gathered}
$$

The optimal consumption allocation remains the same $\left(c_{1}=c_{2}=100\right)$, but the implied level of savings is now $a_{2}=\omega_{1}+T_{1}-c_{1}=10$. The generational accounts associated with the new policy are represented by

$$
g a_{D}(R)=-T_{1}-\frac{1}{R}\left[\tau_{c, 2} c_{2}+\tau_{k} r a_{2}\right]
$$


Depending on the choice of the intertemporal discount rate, the associated generational accounts will have different signs, $g a_{D}(2)=5$ and $g a_{D}(4)=-2.5$. Only for the natural rate are the generational accounts the same across equivalent policies.

Notably, all of these examples share two common features: Alternative fiscal policies redistribute taxes/transfers over the life cycle, and households respond optimally by changing their level of savings. Because the return on savings is taxed, redistribution of the tax burden over the life cycle changes the present value of taxes paid. Only when the government and the private sector discount the future at the same rate are the generational accounts equivalent. While this has an easy fix in this simple economy, the government should always use the natural rate or market rate, $R=1+r$; in more complex economies with heterogeneous agents, there is no connection between the two terms. As a result, the generational accounts will be biased when used to evaluate equivalent policies. This result has two important implications. From the positive point of view, the measurement of tax incidence implied by generational accounts does not provide an accurate description (i.e., an invariant metric) of generational imbalances. From the normative point of view, the evaluation of tax policies based on the distribution of the tax burden for different age cohorts could be misleading with regard to the effective cost for each cohort.

Next, we quantify the potential size of the bias for small deviations in the intertemporal discount rate. For this analysis, we use a fairly standard overlapping-generations model with production.

\section{QUANTITATIVE ASSESSMENT OF THE TAX INCIDENCE BIAS}

In this section, we measure the potential size of the tax incidence bias using a generalized version of the examples in the previous section.

\section{A Standard Life Cycle Model}

Generations live for $I$ periods. Preferences of an individual born in period $t$ are represented by a time-separable utility function of the following form:

$$
U\left(c^{t}, l^{t}\right)=\sum_{i=1}^{I} \beta^{i-1} u\left(c_{i, t+i-1}, 1-l_{i, t+i-1}\right),
$$

where $c_{j, t}$ and $l_{j, t}$ denote consumption and hours worked, respectively, of individuals of age $j$ at time $t$. An individual's subjective discount factor is denoted by $\beta$. The utility function is assumed to be twice continuously differentiable, strictly concave, monotonically increasing in consumption and leisure, and satisfies the standard Inada conditions. At each point in time, households are endowed with one divisible unit of time that can be used for work and leisure. One unit of time of a household of age $i$ transforms into $\varepsilon_{i}$ units of labor input. The time-invariant endowment profile of efficiency units of labor over the life cycle is denoted by $\varepsilon=\left\{\varepsilon_{1}, \ldots, \varepsilon_{l}\right\}$. The population grows at rate $n$.

Individuals supply their labor services and assets in competitive markets. Then, they receive a competitive wage, $w_{t}$, per efficiency unit of labor supplied in period $t$. They also hold assets, $a_{i, t}$, in the form of physical capital or government bonds, in exchange for a market rental rate, $r_{t}$. Clearly, the return of both investments must be the same if households are to hold both types of 


\section{Conesa and Garriga}

assets. We denote the transfer payments received by cohort $j$ as $m_{j, t}$. Notice that this allows transfers to change over the life cycle. $\frac{3}{}$

The production-possibility frontier is represented by a constant returns to scale technology, $Y_{t}=F\left(K_{t}, L_{t}\right)$, that transforms units of capital, $K_{t}$, and efficiency units of labor, $L_{t}=\sum_{i=1}^{I} \mu_{i, t} \varepsilon_{i} l_{i, t}$, into value added. The term $\mu_{i, t}$ represents the relative size of each cohort. The production function is assumed to satisfy the standard Inada conditions. There is no technological progress, and capital depreciates at a constant rate $\delta$. We consider a single representative firm that operates the aggregate technology, taking factor prices $w_{t}, r_{t}$ as given.

Each period production can be used for private consumption, investment, and nonproductive government expenditure. ${ }^{4}$ We take the sequence of government consumption to be exogenously specified. The period resource constraint is then expressed as

$$
C_{t}+(1+n) K_{t+1}-(1-\delta) K_{t}+G_{t}=F\left(K_{t}, L_{t}\right),
$$

where the term $C_{t}=\sum_{i=1}^{I} \mu_{i, t} c_{i, t}$ represents aggregate consumption. The government at each period collects consumption taxes, labor income taxes, capital income taxes, and one-period bonds to finance government expenditure and transfer programs, $T_{t}=\sum_{i=1}^{I} \mu_{i, t} m_{i, t}$. Thus, the
period government budget constraint is given by

$$
\tau_{t}^{c} C_{t}+\tau_{t}^{l} w_{t} L_{t}+\tau_{t}^{k} r_{t} \sum_{i=1}^{I} \mu_{i, t} a_{i, t}+B_{t+1}=\left(1+r_{t}\right) B_{t}+G_{t}+T_{t}
$$

Definition 1. Given a government policy, a market equilibrium in the economy is a sequence of allocations and prices such that (i) consumers maximize utility subject to their budget constraints, (ii) firms maximize profits, (iii) the government budget constraint is balanced, and (iv) markets clear.

In general, it is difficult to characterize the equilibrium path and the optimal decision rules for a given tax policy. In the absence of a closed-form solution, we use numerical methods to simulate the policy reforms and quantify the size of the bias.

The illustration follows Example 1 and performs a neutral Social Security privatization that transforms the unfunded system into a funded one with private accounts following our previous work (Conesa and Garriga, 2008a). In general, an unfunded social insurance system is an intergenerational redistribution scheme, or equivalently, an implicit debt scheme. The young provide resources through contributions that are used to finance the benefits of the retired. Contributions made by the young generate an entitlement to a future benefit upon retirement, which constitutes an implicit debt of the social security system toward them. Upon retirement, these new retirees sell their claims to Social Security benefits to the new cohorts of workers. Consequently, such Social Security privatization only amounts to making explicit the implicit debt. There is no welfare gain associated with this recognition.

However, the choice of the intertemporal discount rate can yield different values for the measures of tax incidence computed for policy A (the unfunded system) and policy B (the funded system). One measure of the size of the bias is the difference between these metrics. 
Table 1

Parameterization of the Economy

\begin{tabular}{lcc} 
Statistic & Target & Result \\
\hline Wealth-to-GDP ratio & 3.00 & 3.00 \\
Investment-to-GDP ratio & 0.16 & 0.16 \\
Average hours worked & 0.33 & 0.33 \\
Debt-to-GDP ratio & 0.50 & 0.50 \\
Government expenditure-to-GDP ratio & 0.20 & 0.20 \\
\hline Variable & & Parameter \\
\hline Discount factor & $\beta$ & Value \\
Consumption share & $\gamma$ & 0.984 \\
Depreciation rate & $\delta$ & 0.460 \\
Labor income tax & $\tau^{\prime}$ & 0.041 \\
\end{tabular}

\section{Parameterization}

Next we determine the choice of functional forms and parameters for the model simulation.

Functional Forms. We pose a standard log utility function between consumption and leisure:

$$
u(c, l)=\gamma \ln c+(1-\gamma) \ln (1-l),
$$

where $\gamma$ represents the consumption share on the utility function.

The aggregate technology is Cobb-Douglas with constant returns to scale:

$$
F(K, L)=K^{\alpha} L^{1-\alpha}
$$

where $\alpha=1 / 3$ represents the capital income share in output.

Population Structure and Income. A model period is equivalent to one year. Given our period choice, we assume households (i) live for 65 periods so that the economically active life of a household starts at age 20 and (ii) die with certainty at age 85. In the benchmark economy, households retire in period 45 (equivalent to 65 years of age). Finally, we normalize the mass of households to be 1 . We assume that households are endowed with one unit of time. The lifetime profile of efficiency units is constructed using Current Population Survey data.

Government Policy. The level of government expenditure is exogenously specified as 20 percent of output. Revenue is derived from two sources: (i) capital and labor income taxes and (ii) consumption taxes. In addition, the government administers a pay-as-you-go social security system in the benchmark policy scenario. We assume that the tax on capital income is 33 percent, social security contributions are 10.5 percent of labor income, and consumption taxes are 5 percent. The labor income tax is chosen to balance the government budget given the target level of outstanding government debt. 


\section{Conesa and Garriga}

Figure 1

Asset Distributions (Relative to Yearly Income)



Given the assumptions on the functional forms, endowments, and tax rates, we jointly solve for the equilibrium and the parameterization to match target statistics. Table 1 defines the parameter values and the targets.

We want our economy to match three empirical targets. First, we define aggregate capital as the level of fixed assets in the Bureau of Economic Analysis statistics, giving an implied capitalto-output ratio of 3.00. The second target is an investment-to-output ratio of 16 percent. The third target is the average number of hours worked over the life cycle, with an average of onethird (0.33) of the time of households allocated to market activities. In addition, we fix government debt (defined as federal, state, and local) with an implied government debt-to-gross domestic product (GDP) ratio of 0.50 and a government expenditure-to-GDP ratio of 0.20 .

Our three targets determine the value of three parameters: the discount factor, the consumption share in the utility function, and the depreciation rate. In addition, the labor income tax is endogenously determined from the government's budget constraint given the ratios of government debt and expenditure to GDP.

\section{Equivalent Tax Reforms: The Case of a Neutral Social Security Reform}

The fiscal reform we examine follows our previous work (Conesa and Garriga, 2008a) and illustrates the measurement discrepancies generated by the standard generational accounting procedure. The goal is to privatize the social security system while maintaining the level of dis- 


\section{Figure 2}

\section{Net Taxes Paid (Relative to Yearly Income)}

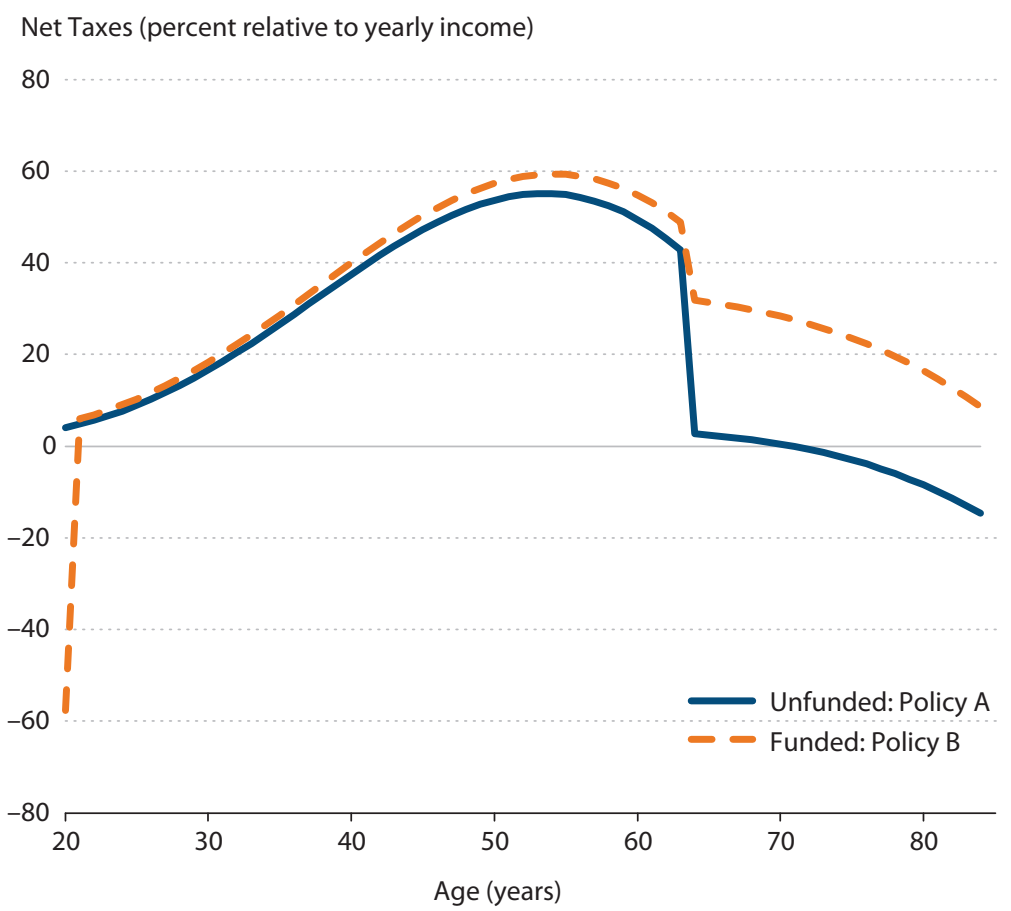

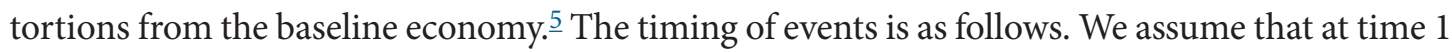
the economy is in steady state with an unfunded social security system. The contributions made by working cohorts generate an entitlement to a future benefit upon retirement, which constitutes an implicit debt of the social security system toward them. Upon retirement, these retirees receive their claims.

The reform is implemented at time 2 . The government eliminates pensions and gives compensatory transfers to all households. These household-specific transfers are financed with government debt. The anticipation of the reform is a nonissue in this exercise. The reform does not alter households' intertemporal budget constraint. The privatization effectively transforms the implicit debt of the social security system into explicit debt, but real allocations and welfare remain unchanged. The resulting distribution of wealth is different, since now the implicit social security claims are transformed into explicit assets in the hands of households. Figure 1 compares distributions of wealth under both policies.

The asset distribution under the funded system (policy B) is always above the unfunded one (policy A) because workers use the proceeds from social security contributions to invest in private savings accounts. The youngest cohort receives a transfer of an initial level of assets equivalent to the net present value of social security transfers. This amount ensures that the consumer intertemporal budget constraint is satisfied. The difference between the newly issued government bonds and the initial outstanding government debt determines the implicit debt of the 


\section{Conesa and Garriga}

\section{Figure 3}

\section{Generational Accounts for Different Intertemporal Rates $\boldsymbol{R}$}
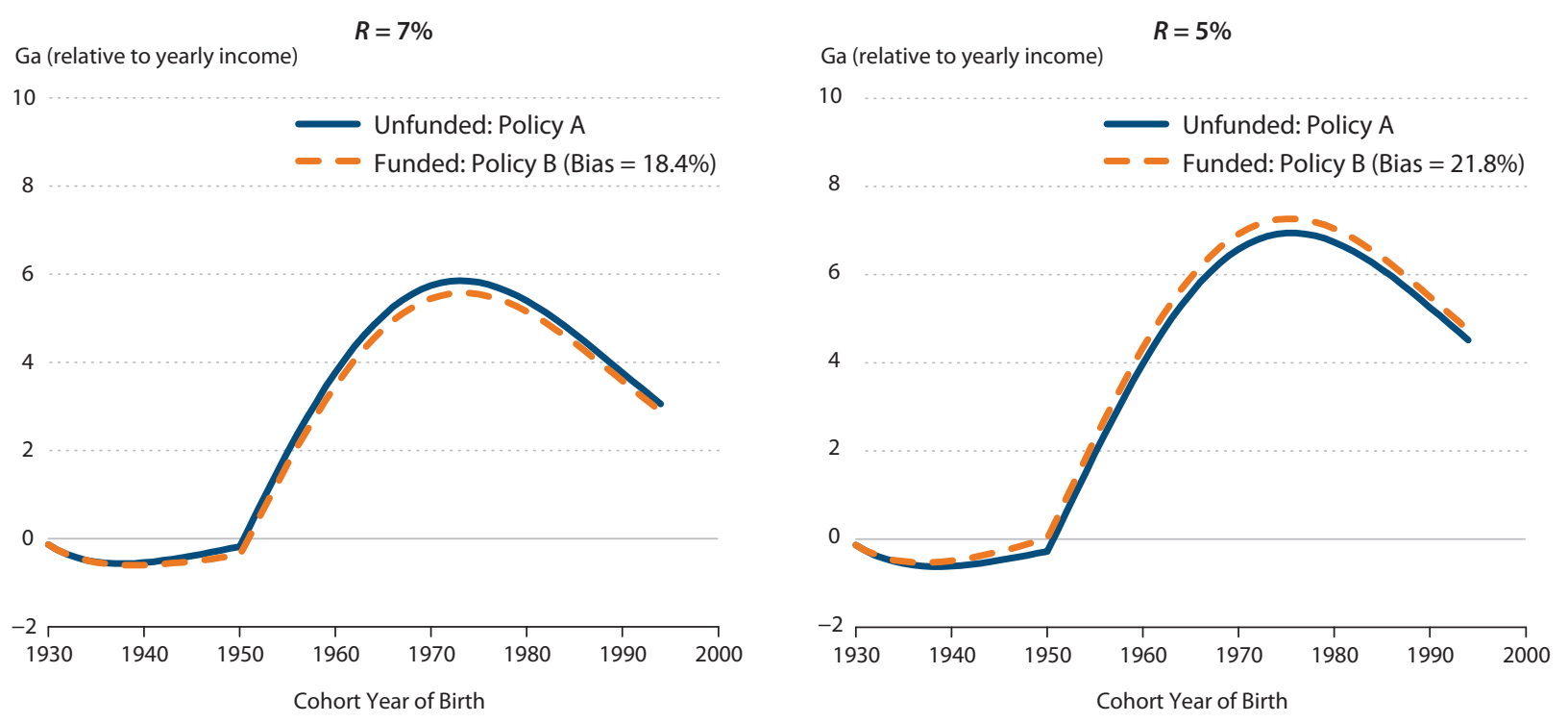

NOTE: Ga, generational accounting measure of tax burden.

social security system. Figure 2 shows the net taxes paid over the life cycle in these two equivalent policy regimes.

Under the unfunded social security system, the entire tax burden is on individuals 65 years of age and younger. Retired households pay consumption and capital income taxes, but in net terms they receive resources (their pensions). Under the new regime, retired households do not receive a transfer from the government, and they are fully taxed for the interest earned in their retirement accounts. Despite the differences in the amount of taxes paid, the welfare distribution is the same across tax regimes. Using the net taxes paid and the relative size of each cohort, we can compute the generational accounts of each cohort based on the cohort's age.

Figure 3 summarizes the model-implied generational accounts for these two equivalent social security regimes for different intertemporal discount rates. Notice that the standard generational accounting procedure is not invariant between these two equivalent policy regimes because the two top curves in the figure do not lie on top of each other. Furthermore, the order can be reversed depending on the discount rate. With a high intertemporal discount rate, $R=7$ percent, policy B seems to reduce the tax burden of the current cohorts; but, with a lower discount rate, the opposite is true.

The bias is driven purely by the fact that government bond holdings are larger in the funded regime when they are not net wealth. Because capital income (derived from holding government debt or financial assets) is taxed, the imputed tax burden varies across the two policy regimes. However, the proceeds from selling the government bonds are, by construction, equal to the transfers received from the social security system. The difference is that transfers under the 


\section{Figure 4}

\section{Generational Accounts with No Bias $\left(R=R^{*}\right)$ (Relative to Yearly Income)}

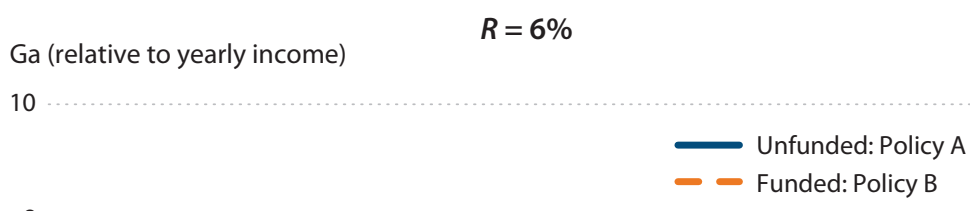

8

- Funded: Policy B

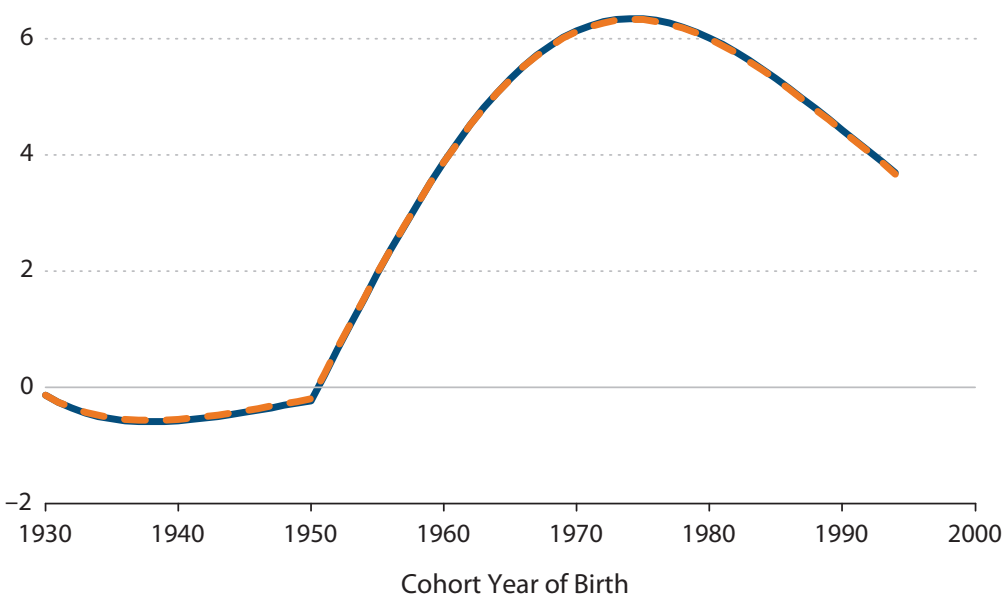

NOTE: Ga, generational accounting measure of tax burden.

equivalent policy are computed as a taxable asset and an explicit government liability that lasts forever. In contrast, net transfers from the government are funded by workers' contributions and become an implicit government liability. The latter situation creates a bias as long as the intertemporal discount rate does not equate both lines. In the simulations, the magnitude of the bias can easily range between 18 and 22 percent. In this type of policy comparisons with no real effects, an intertemporal discount rate exists that guarantees this is the case (Figure 4), but any deviation from this rate generates a bias.

In this article, we have assumed that markets are complete. That is, households are allowed to trade assets to smooth consumption over the life cycle. The choice of the intertemporal discount rate is more challenging in more complex economies with heterogeneous agents or in economies in transition dynamics where the interest rates vary over time. However, the findings in this article do not depend on these model features.

\section{CONCLUSION}

As the number of retirees in the United States doubles over the next 25 years, the number of employees in the workforce will grow by only 20 percent. This demographic transition surely will have an important effect on the federal budget unless Social Security and Medicare benefits 


\section{Conesa and Garriga}

are reduced. The determination of which cohorts will bear the cost is important, but agreement on how to measure generational imbalances is needed first.

We show that the choice of the intertemporal discount rate is very problematic in assessing the fiscal burden of different age cohorts; it affects not only the magnitude but also the sign of policy rankings based on this metric. In the simulations, the size of the bias easily ranges between 18 and 22 percent.

\section{NOTES}

1 Welfare analysis is an alternative method to measure tax incidence. This approach requires specific assumptions about preferences and technology and is based entirely on individual optimizing behavior and market-clearing conditions. Conesa and Garriga (2008b) use optimal fiscal policy to design the best possible response to demographic shocks.

$\underline{2}$ A similar approach has been used by the economists at the Board of Governors of the Federal Reserve System. They have developed a stylized model to measure the impact of population aging on living standards using consumption growth. For example, Bernanke (2006) summarizes the findings of Elmendorf and Sheiner (2000) and Sheiner, Sichel, and Slifman (2006) and proposes alternatives to deal with the demographic transition.

3 We do not restrict the sign of government transfer programs for workers and retirees. This is irrelevant because the focus of our article is the measurement of the tax incidence over different cohorts, not the distortionary effect of different tax instruments on these individuals.

4 We choose to have a nonproductive government expenditure with a benchmark comparable to the generational accounting methodology.

$\underline{5}$ Clearly, it is possible to achieve better policy results by optimizing distortions, as in our previous work (Conesa and Garriga, 2008a), where we use optimal fiscal policy to do precisely that.

\section{REFERENCES}

Altig, David; Auerbach, Alan J.; Kotlikoff, Laurence J.; Smetters, Kent A. and Walliser, Jan. “Simulating Fundamental Tax Reform in the United States." American Economic Review, June 2001, 91(3), pp. 574-95.

Auerbach, Alan J.; Gokhale, Jagadeesh and Kotlikoff, Laurence J. “Generational Accounts: A Meaningful Alternative to Deficit Accounting." Tax Policy and the Economy, 1991, 5, pp. 55-110.

Bernanke, Ben S. "The Coming Demographic Transition: Will We Treat Future Generations Fairly?" Presented at the Washington Economic Club, Washington, DC, October 4, 2006; http://www.federalreserve.gov/newsevents/speech/bernanke20061004a.htm.

Cardarelli, Roberto; Sefton, James and Kotlikoff, Laurence J. "Generational Accounting in the UK." Economic Journal, November 2000, 110(467), pp. 547-74.

Conesa, Juan C. and Garriga, Carlos. "Optimal Fiscal Policy in the Design of Social Security Reforms." International Economic Review, February 2008a, 49(1), pp. 291-318.

Conesa, Juan C. and Garriga, Carlos. "Optimal Response to a Transitory Demographic Shock," in Robert Fenge, Georges de Ménil, and Pierre Pestieau, eds., Pension Strategies in Europe and the United States. Cambridge, MA: MIT Press, 2008b, pp. 87-113.

Conesa, Juan C. and Garriga, Carlos. "Optimal Intergenerational Policy and Measures of Tax Incidence." Unpublished manuscript, Federal Reserve Bank of St. Louis, 2013.

Elmendorf, Douglas W. and Sheiner, Louise, M. "Should America Save for Its Old Age? Fiscal Policy, Population Aging, and National Saving." Journal of Economic Perspectives, Summer 2000, 14(3), pp. 57-74.

Fehr, Hans and Kotlikoff, Laurence J. "Generational Accounting in General Equilibrium." FinanzArchiv/Public Finance Analysis, 1996, 53, pp. 1-27. 
Gokhale, Jagadeesh; Page, Benjamin R.; Potter, Joan and Sturrock, John R. "Generational Accounts for the United States: An Update." American Economic Review, May 2000, 90(2), pp. 293-96.

Kotlikoff, Laurence J. "Generational Policy," in Alan J. Auerbach and Martin Feldstein, eds., Handbook of Public Economics. Volume 4, Chap. 27. Amsterdam: Elsevier, 2002, pp. 1873-932.

Kotlikoff, Laurence J. and Raffelhüschen, Bernd. "Generational Accounting Around the Globe." American Economic Review, May 1999, 89(2), pp. 161-66.

Kotlikoff, Laurence J.; Smetters, Kent and Walliser, Jan. “Distributional Effects in a General Equilibrium Analysis of Social Security," in Martin Feldstein and Jeffrey B. Liebman, eds., The Distributional Aspects of Social Security and Social Security Reform. Chicago: University of Chicago Press, 2002, pp. 327-69.

Sheiner, Louise; Sichel, Daniel and Slifman, Lawrence. "A Primer on the Macroeconomic Consequences of Population Aging." Finance and Economics Discussion Series Working Paper No. 2007-01. Divisions of Research and Statistics and Monetary Affairs, Federal Reserve Board, September 2006;

http://www.federalreserve.gov/pubs/feds/2007/200701/200701pap.pdf. 
